\title{
A new strain of Volutella citrinella with nematode predation and nematicidal activity, isolated from the cysts of potato cyst nematodes in China
}

\author{
Xinyue Zhang ${ }^{1}$, Hui Zhang ${ }^{1}$, Zhaochun Jiang ${ }^{2}$, Qing Bai ${ }^{1}$, Shishi Wu ${ }^{1}$, Yong Wang ${ }^{1}$, Cheng Li ${ }^{1}$, Xiangyu Zeng ${ }^{1}$,
} Xiuhai Gan ${ }^{3}$, Xin Xie ${ }^{1}$, Zhong $\mathrm{Li}^{1}$ and Zaifu Yang ${ }^{1 *}$

\begin{abstract}
Background: Plant parasitic nematodes (PPNs) are responsible for causing many plant diseases and are extremely difficult to control at present. Currently, due to the negative effects of chemical agents on the environment and human health, the development of new biological pesticides has become an important part of plant nematode control. Nematophagous fungi refers to a class of fungi that kill plant nematodes. Notably, a large number of nematophagous fungi resources remain to be studied. The objective of our study was to use in vitro screening to identify nematophagous fungi and select strains that were highly active against nematodes, providing a primary research for the development and utilization of new nematophagous fungi.

Results: A new nematophagous fungal strain (GUCC2219) was isolated from cysts of possibly Globodera spp. and Heterodera spp., identified as Volutella citrinella. The hyphae of $V$. citrinella produced ring structures of variable size and exhibited predatory and nematicidal activity. The hyphal predation rates (in vitro) against three species of nematodes, Aphelenchoides besseyi, Bursaphelenchus xylophilus, and Ditylenchus destructor, averaged 59.45, 33.35, and 50.95\%, respectively, while the fermentation broth produced by the fungus exhibited mortality rates of 100, 100, and 55.63\%, respectively, after $72 \mathrm{~h}$.
\end{abstract}

Conclusion: V. citrinella is a new strain with nematophagous properties, which are a novel discovery. At the same time, this is the first report of nematicidal and nematode predation activity in the genus Volutella.

Keywords: Biocontrol, Nematophagous fungi, Plant parasitic nematode, Volutella citrinella

\section{Background}

Plant parasitic nematodes (PPNs) are major pathogens of many crops and comprise more than 4100 species globally [1]. Nematodes feed on a wide range of important agricultural crops, including wheat, rice, soybeans, potatoes, tomatoes and sugar beets [2]. A variety of

\footnotetext{
*Correspondence: zfyang@gzu.edu.cn

${ }^{1}$ Department of Plant Pathology, College of Agriculture, Guizhou

University, Guiyang, Guizhou, China

Full list of author information is available at the end of the article
}

aboveground symptoms become evident after nematodes have infected the root system of a plant, such as leaf discoloration, leaf spot, wilting, stunted growth, and increased susceptibility to other pathogens [2-4]. Plant diseases caused by nematodes have gradually become a main limiting factor for crop yield and quality and have been the cause of significant economic losses ( $\$ 80$ billion/year) globally [5-7].

Species of plant nematodes that impact agriculture include cyst nematodes (Globodera and Heterodera spp.), 
root knot nematodes (Meloidogyne spp.), foliar nematodes (Aphelenchoides spp.), pine wilt nematode (Bursaphelenchus xylophilus), Ditylenchus destructor, Anguina tritici [8-10]. Among them, A. besseyi, B. xylophilus and $D$. destructor are especially important in China. Aphelenchoides besseyi mainly damages rice, whose leaves exhibit white tips after becoming infected and then become necrotic. The flagged leaves are curled and deformed, inflorescences are reduced in size and the heads do not develop mature grains, resulting in a decrease in yield [11]. Yield can be reduced in severe cases by as much as $60 \%$ [12]. In fact, $A$. besseyi has been listed as one of the ten most harmful plant nematodes due to its potential impact on yield [13]. Bursaphelenchus xylophilus is responsible for causing many tree diseases globally [14] and is classified as a quarantine pathogen by most countries in the world [15]. It is also listed among the ten most harmful plant nematodes [13]. It is mainly spread by the beetle Monochamus alternatus feeding on healthy pine trees [16]. When the pine wood nematode enters the stem of pine trees, it migrates through resin canals feeding on parenchyma cells, ultimately killing the host tree [17]. It is responsible for causing hundreds of millions of dollars in economic losses globally, including in Japan, the United States, and Canada [18, 19]. Ditylenchus destructor is also one of the most destructive plant pathogenic nematodes [20]. It can parasitize more than 120 host plants in China and is one of the main pathogens of potatoes and sweet potatoes [21], causing a 20 to $50 \%$ yield reduction and even $100 \%$ crop loss in endemic areas [22]. In summary, the economic losses caused by the three plant nematodes distributed to China and even the whole world should not be underestimated. At the same time, they damage plant leaves; the inside of plants and plant tubers respectively. So, they can be used as representative PPNs that damage different parts of plants. Therefore, the effective control methods for these three plant nematodes may also be applicable to other plant nematodes.

Due to the negative effects of chemical agents on the environment and human health, certain chemical agents have been recently restricted or banned [23], and thus, the development of new biological pesticides has become an important part of plant nematode control [24]. Nematophagous fungi refers to a class of fungi that have the ability to parasitize, capture, colonize, and produce toxins that kill plant nematodes [25]. To date, more than 700 species of nematophagous fungi have been reported around the world [26], which were distributed multiple genera (Additional file 1: Schedule 1). Although there are so many types, there are few commercial products that have been successfully developed into biocontrol preparations, and the number of biocontrol preparations used in production is not many [27]. In addition, a large number of nematophagous fungi remain to be discover in nature [28, 29]. Therefore, the excavation of new nematophagous fungi is of great significance to natural resources and the development of biological pesticides.

Approximately 380 species of nematode-trapping fungi have been reported from different regions of the world [25]. However, there is no report about the fungi of the genus Volutella as nematode-trapping fungi. Volutella is a widespread genus of the Nectriaceae family and approximately 120 described species of Volutella have been identified from various parts of the world [30]. The genus Volutella is poorly researched despite the common occurrence and broad distribution of these species [31]. According to reports, $V$. citrinella (Stilbella aciculosa [32]) oxidizes Mn (II) to Mn oxides by producing extracellular superoxide during cell differentiation and this microbial extracellular superoxide production may play a central role in the cycling and bioavailability of metals (e.g., $\mathrm{Hg}, \mathrm{Fe}, \mathrm{Mn}$ ) and carbon in natural systems [33]. In addition, Osono and Takeda [34] reported that $V$. ciliata plays an important role in plant litter decomposition in forest ecosystems through soil nutrient recycling and the accumulation of organic matter in soil. However, other species of the genus can cause a variety of plant diseases, such as Volutella pachysandricola causing Volutella blight (sometimes called leaf blight and stem canker) on Japanese pachysandra (Pachysandra terminalis) [35]; V. buxi causing Boxwood Volutella stem blight or canker on boxwood (Buxus spp.) [36]. There were beneficial microorganisms and plant pathogens in the fungus of the genus Volutella, which are worthy of further study.

In the present research, colonizing microorganisms were isolated from cysts of possibly Globodera spp. and Heterodera spp. of potatoes growing in Weining County, Guizhou Province, China. A total of 147 isolates were obtained, mainly fungi. Their nematicidal properties were evaluated by in vitro screening. One isolate (GUCC2219) was found to exhibit high hyphal predation rates in vitro against Aphelenchoides besseyi, Bursaphelenchus xylophilus, and Ditylenchus destructor, with predation rates averaging 59.45, 33.35, and $50.95 \%$, respectively, while its fermentation broth exhibited mortality rates of 100,100 , and $55.63 \%$, respectively, after $72 \mathrm{~h}$. The GUCC2219 fungal isolate was identified as Volutella citrinella based on morphological observations and phylogenetic analysis of the genetic sequence of the internal transcribed spacer (ITS) and large subunit (LSU) regions of DNA. This is the first report of nematicidal and nematode predation activity in the genus Volutella. 


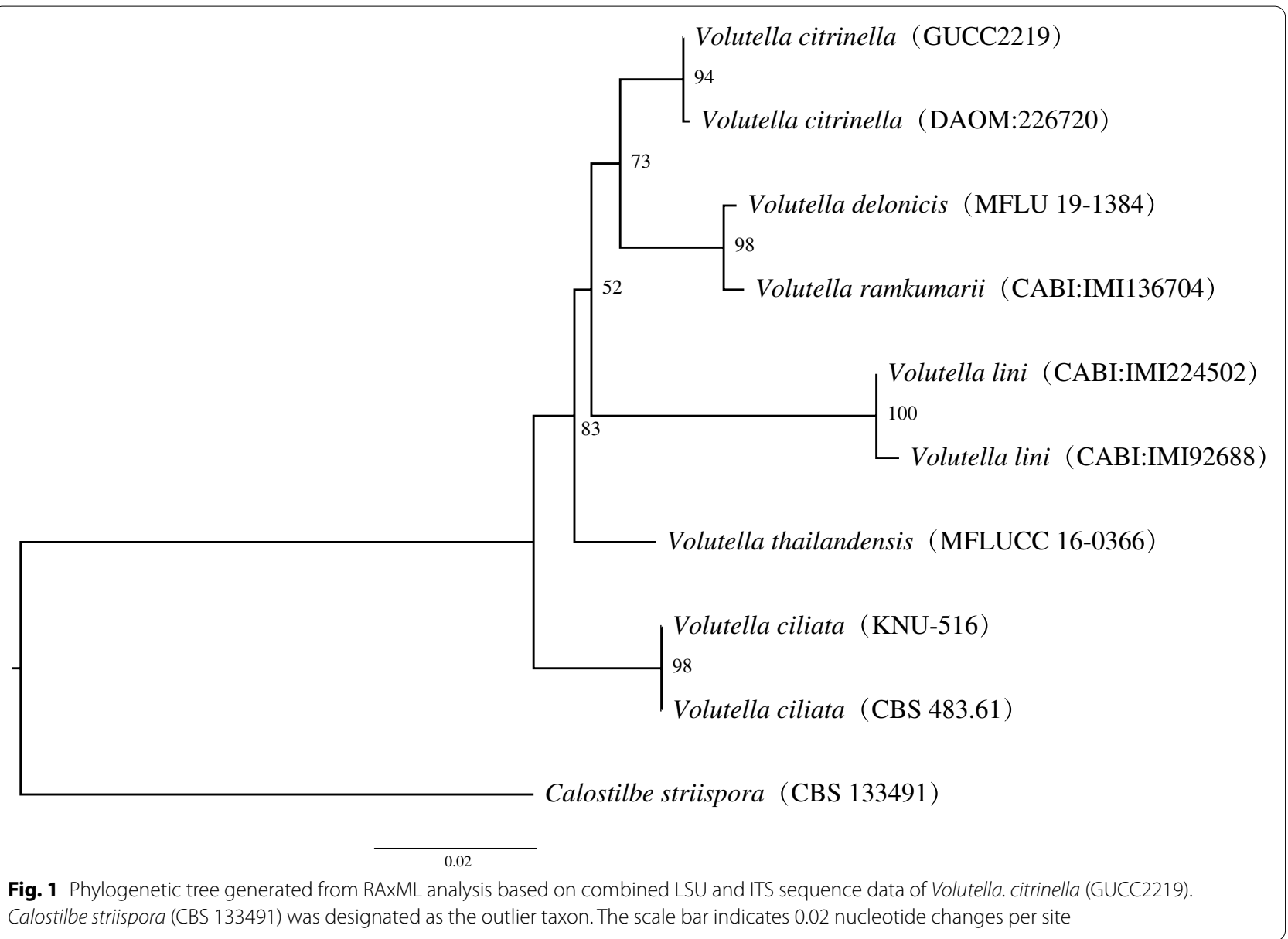

\section{Results}

\section{Fungi identification (GUCC2219)}

The sequences of the polymerase chain reaction (PCR) products obtained from strain GUCC2219 were uploaded to GenBank and subjected to Basic Local Alignment Search tool (BLAST) analysis. The highest similarity was obtained to accession numbers MZ148447 (ITS) and MZ148449 (LSU). In the phylogenetic tree (Fig. 1), GUCC2219 clustered with the type culture of Volutella citrinella (DAOM: 226720) and exhibited high sequence similarity, $99 \%(530 / 531)$ and $100 \%(877 / 877)$ to its ITS and LSU gene regions, respectively.

Morphological observations were made after the GUCC2219 strain was cultured on potato dextrose agar (PDA) and cornmeal agar (CMA) for 14 days at $25^{\circ} \mathrm{C}$. Observations indicated that colonies were superficial on PDA, reaching $20-30 \mathrm{~mm}$ diam. A purple-red pigment was produced on the underside of the colony (Fig. 2a, b). More purple-red pigment was evident when GUCC2219 was cultured on CMA than when it was cultured on PDA. Conidial masses that formed on the surface were yellowwhite. Synnemata were lightly colored, 350-1300 $\mu \mathrm{m}$ tall, and $26-40 \mu \mathrm{m}$ wide (Fig. 2c, d, e). Conidiogenous cells and phialides were $12-20$ (length) $\times 2-3 \mu \mathrm{m}$ (width) (Fig. 2f-k). Conidia were ellipsoidal to oblong-ellipsoidal and 4.5-7 (length) $\times 2-3.5$ (width) $\mu \mathrm{m}$ in size (Fig. 2l) . Marginal hyphae were verrucose near the capitulum (Fig. $2 \mathrm{~m}$ ). No aerial mycelia or chlamydospores were observed on PDA or CMA. These morphological characteristics were somewhat different from those described for $V$. citrinella by Rezakhani et al. [37]., who described the size of synnemata as $300-1450 \mu \mathrm{m}$ tall and $25-50 \mu \mathrm{m}$ wide and the size of the conidiogenous cells and conidia as $13-25 \times 1.5-2 \mu \mathrm{m}$ and $3-5 \times 1-2 \mu \mathrm{m}$, respectively. Despite these differences, however, we felt that the combined morphological observations and phylogenetic analysis confirmed isolate GUCC2219 to be a strain of $V$. citrinella.

\section{In vitro predatory activity of $V$. citrinella (GUCC2219) against nematodes}

Microscopic examination of $V$. citrinella (GUCC2219) at $1 \%$ water agar (WA) revealed that it produced a large number of hyphal rings through the twining of mycelia 

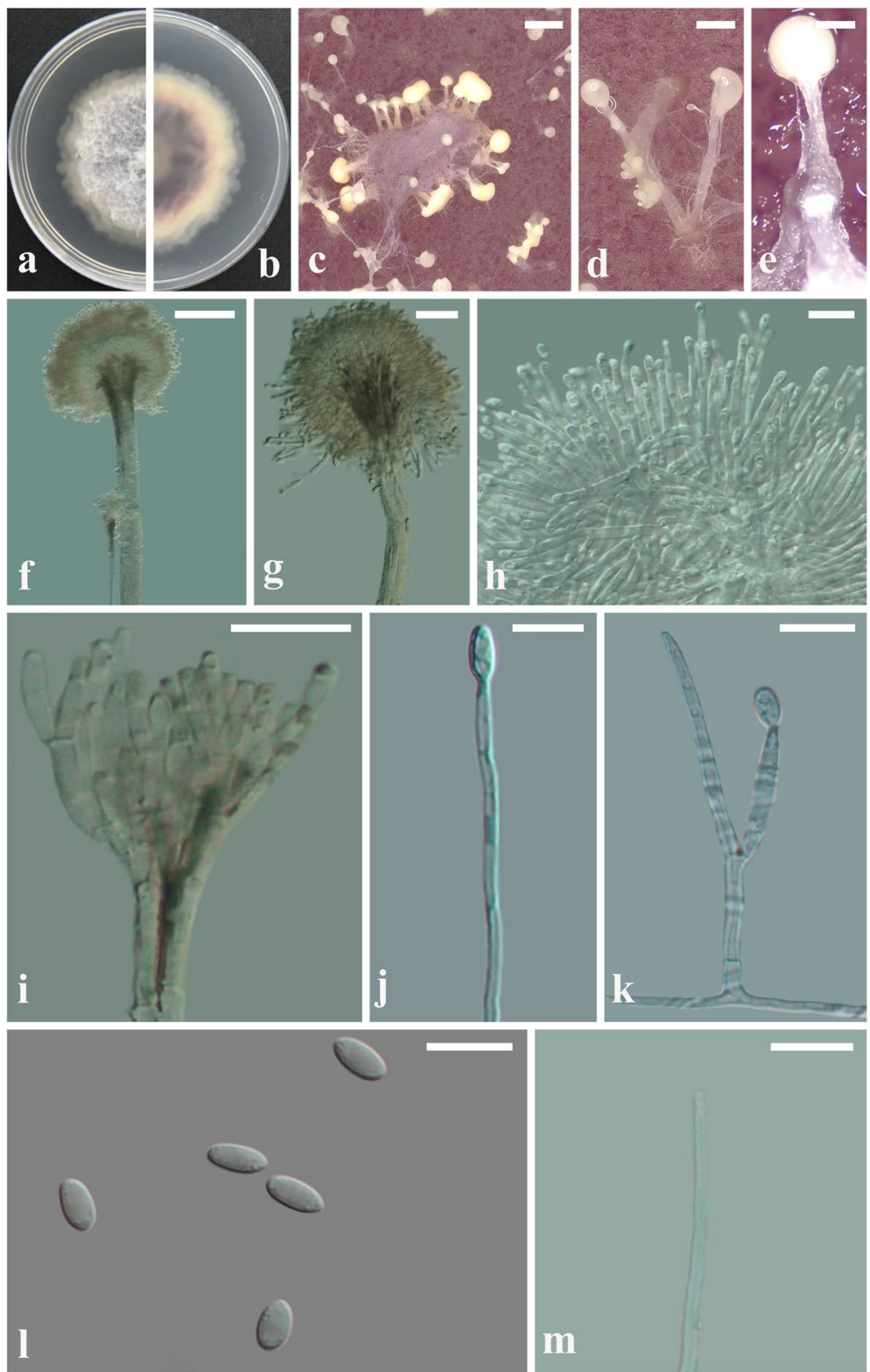

Fig. 2 Colony and microscopic features of Volutella. citrinella (GUCC2219). a, b. Top and bottom images of GUCC2219 cultured on PDA for 15 d. c, d, e. Purple pigment and yellowish slime of the synnemata of colonies growing on CMA. f-k. Conidiogenous cells. I. Conidia. m. Seta-like marginal hypha in culture. Scale bars: $c=1000 \mu m, d, e=100 \mu m, f, g, i, j=50 \mu m, h, k, l, m=10 \mu m$

(Fig. 3a). There were three types: small, regular-shaped (Fig. 3b, c), large regular-shaped rings (Fig. 3d, e), and irregularly shaped rings of various sizes (Fig. 3f, g). Measurements of the rings indicated that the average diameters of the outer and inner rings were $26.40 \mu \mathrm{m}$ and $12.24 \mu \mathrm{m}$, respectively. The average thickness of mycelial twining was $7.75 \mu \mathrm{m}$. Sizes were based on the measurement of 100 randomly sampled rings (Table 1).
The quantity of the rings did not increase after the fungal cultures were inoculated with nematodes. Nematodes moved freely on WA plates of GUCC2219 cultures during the first $12 \mathrm{~h}$ of coincubation, and little change occurred in the morphology of the rings. Between 12 and $24 \mathrm{~h}$, however, the movement of the nematodes began to become limited, and the rings turned a golden color when a nematode became 

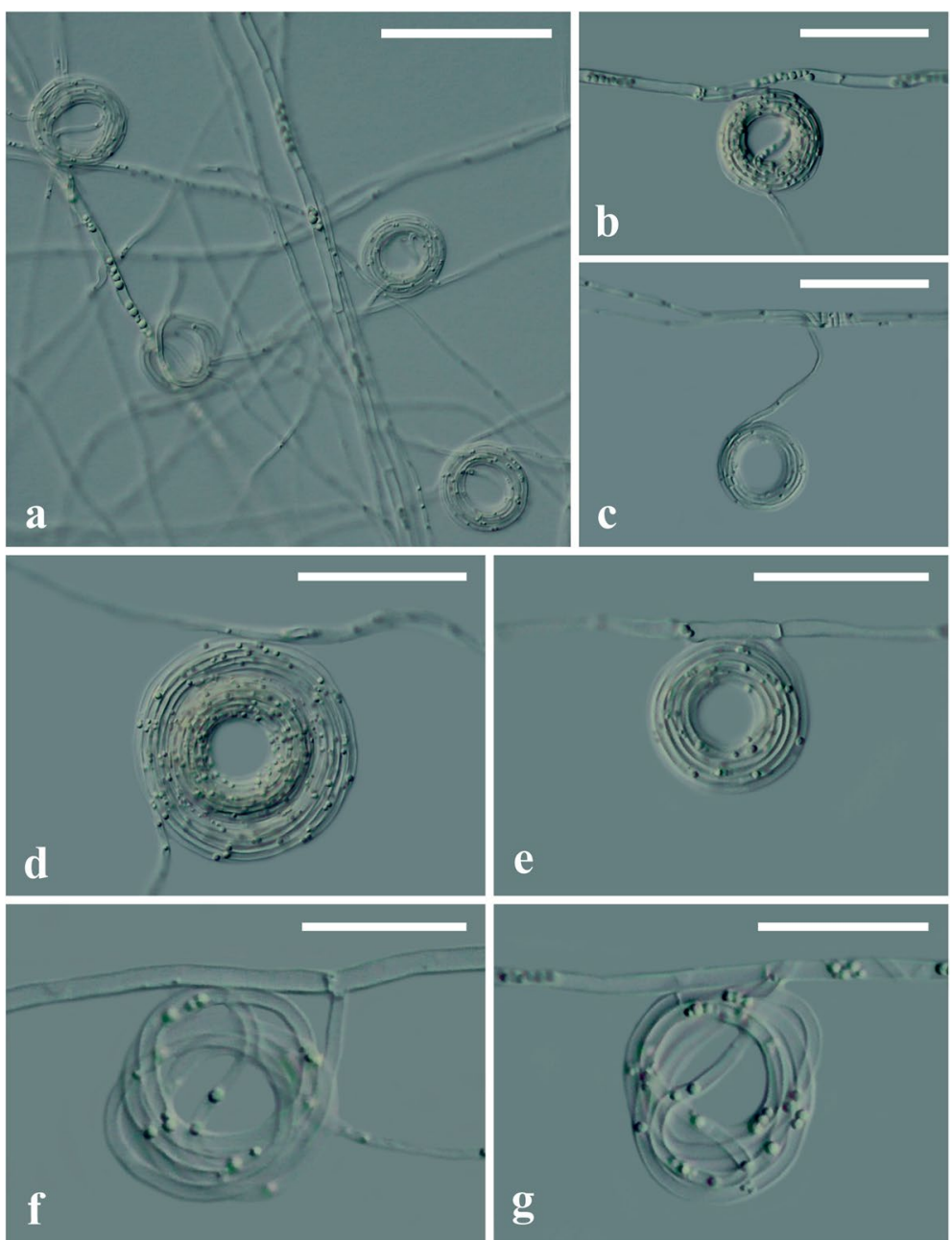

Fig. 3 a. Ring structures of Volutella. citrinella (GUCC2219) cultured on water agar (WA). b, c. Small, regular-shaped ring structures. d, e. Large regular-shaped ring structures. $\mathbf{f}, \mathbf{g}$. Irregular-shaped ring structures. Scale bars $=50 \mu \mathrm{m}$

Table 1 Diameter $(\mu \mathrm{m})$ of inner and outer rings and thickness of individual hyphae making up the ring structures produced by Volutella citrinella (GUCC2219)

\begin{tabular}{lll}
\hline Ring size & Mean $(\boldsymbol{\mu m})$ & $\begin{array}{l}\text { Range }(\boldsymbol{\mu m}) \\
(\boldsymbol{n}=\mathbf{1 0 0})\end{array}$ \\
\hline Diameter of outer ring & $26.40 \pm 6.69$ & $15.69-61.89$ \\
Diameter of inner ring & $12.24 \pm 3.03$ & $6.61-33.20$ \\
Thickness of mycelium winding & $7.75 \pm 2.57$ & $4.27-22.11$ \\
\hline
\end{tabular}

${ }^{a}$ Data represent the mean $\pm \operatorname{SE}(n=4)$

entrapped. Nematodes became entangled and completely entrapped (could not move) due to their increased entanglement with hyphae after $24-48 \mathrm{~h}$ of coincubation. Two days later, the hyphae had started to attach to the surface of entrapped nematodes and completely engulf them. After $72 \mathrm{~h}$ of coincubation, the number of fungal mycelia composing the rings increased, the body wall of the entrapped nematodes dissolved, the internal contents of the nematodes consumed, and only traces of the entrapped nematodes remained (Fig. 4a-1).

Under in vitro conditions, the GUCC2219 strain of $V$. citrinella was cultured on 1\% WA and separately coincubated with three different species of nematodes. The number of total nematodes entrapped in five independent microscopic fields of view was recorded over $72 \mathrm{~h}$. The results indicated that $V$. citrinella (GUCC2219) exhibited significant predatory activity against the three species of nematodes at different points in time. In general, the percentage of trapped nematodes increased with the time of coincubation for all three species of nematodes (Table 2). The predation activity of $V$. citrinella (GUCC2219) was greatest against $A$. besseyi, with an average percentage of $59.45 \%$ at $72 \mathrm{~h}$, followed by $D$. 


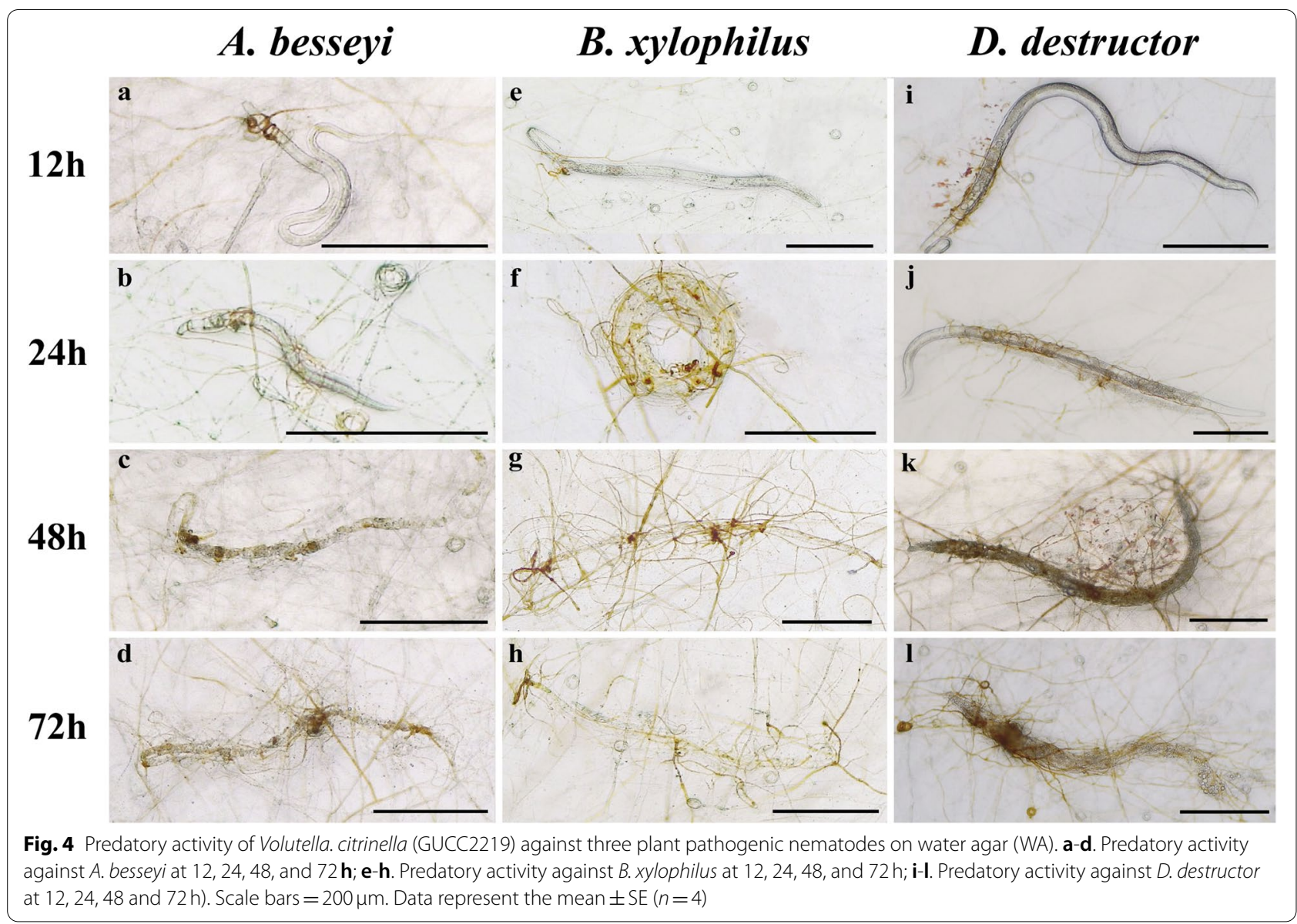

Table 2 The predation rate of Volutella citrinella (GUCC2219) against three species of plant pathogenic nematodes on water agar

\begin{tabular}{llllll}
\hline Nematodes & Treatment & \multicolumn{3}{l}{ Incubation Time (h) } \\
\cline { 3 - 6 } & & $\mathbf{1 2}$ & $\mathbf{2 4}$ & $\mathbf{4 8}$ & $\mathbf{7 2}$ \\
\hline A. besseyi & Control & $3.50 \pm 0.50 \mathrm{~b}$ & $5.50 \pm 0.96 \mathrm{~b}$ & $9.50 \pm 1.26 \mathrm{~b}$ & $10.67 \pm 0.67 \mathrm{~b}$ \\
& GUCC2219 & $13.88 \pm 0.87 \mathrm{a}$ & $22.37 \pm 2.05 \mathrm{a}$ & $37.67 \pm 3.17 \mathrm{a}$ & $59.45 \pm 3.76 \mathrm{a}$ \\
B. xylophilus & Control & $6.50 \pm 0.96 \mathrm{~b}$ & $7.50 \pm 0.50 \mathrm{~b}$ & $9.50 \pm 1.50 \mathrm{~b}$ & $11.00 \pm 1.73 \mathrm{~b}$ \\
& GUCC2219 & $19.66 \pm 2.40 \mathrm{a}$ & $27.04 \pm 2.19 \mathrm{a}$ & $32.40 \pm 2.11 \mathrm{a}$ & $33.35 \pm 0.96 \mathrm{a}$ \\
D. destructor & Control & $2.00 \pm 1.15 \mathrm{~b}$ & $3.00 \pm 1.00 \mathrm{~b}$ & $5.00 \pm 1.91 \mathrm{~b}$ & $8.00 \pm 1.63 \mathrm{~b}$ \\
& GUCC2219 & $8.64 \pm 1.13 \mathrm{a}$ & $17.65 \pm 2.34 \mathrm{a}$ & $30.98 \pm 0.98 \mathrm{a}$ & $50.95 \pm 2.21 \mathrm{a}$ \\
\end{tabular}

*Note: Data represent the mean \pm SE $(n=4)$. Different lowercase letters indicate a significant difference $(P<0.05)$ between the control and GUCC2219 strains within a species and within a given time point

destructor and B. xylophilus, with averages of 50.95 and $33.35 \%$, respectively $(P<0.05)$.

\section{Nematicidal activity of the V. citrinella (GUCC2219) fungal fermentation filtrate}

The nematicidal activity of the V. citrinella (GUCC2219) fermentation filtrate was significantly different from that of the potato dextrose broth (PDB) medium alone (Fig. 5), the latter of which exhibited no nematostatic or nematicidal activity as nematode mortality in PDB was statistically similar to that in sterilized water $(\mathrm{P}<0.05)$.

The nematicidal activity of the undiluted fermentation filtrate of $V$. citrinella (GUCC2219) was the highest against $A$. besseyi, producing mortality levels of 21 , 27,100 , and $100 \%$ at $12,24,48$, and $72 \mathrm{~h}$, respectively (Fig. 5A). The mortality rate in Bursaphelenchus xylophilus also increased rapidly, being 10, 59, 69 and 100\% at $12,24,48$, and $72 \mathrm{~h}$, respectively (Fig. 5B). Ditylenchus 


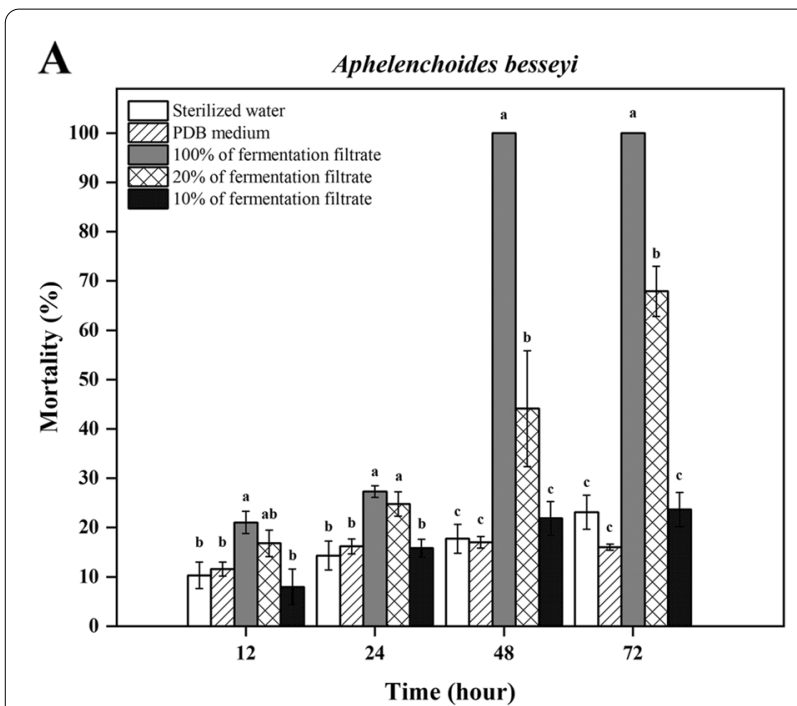

B

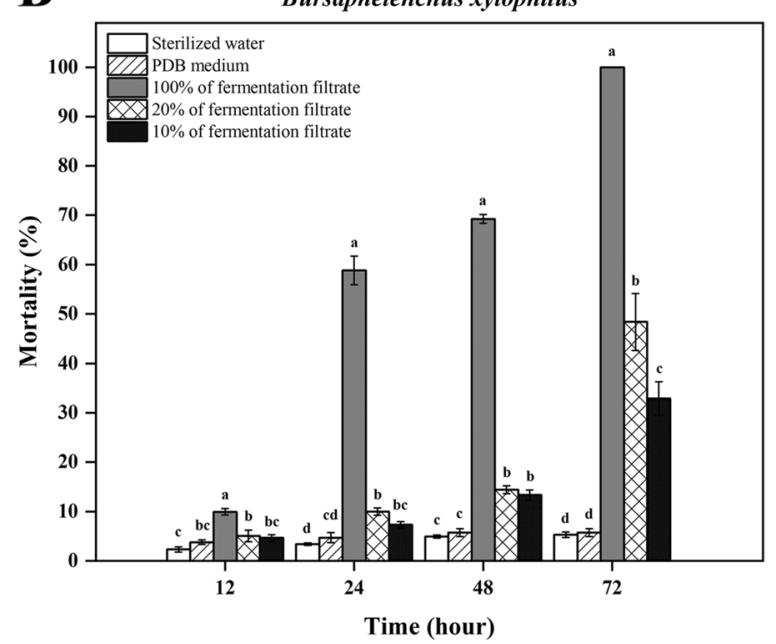

C

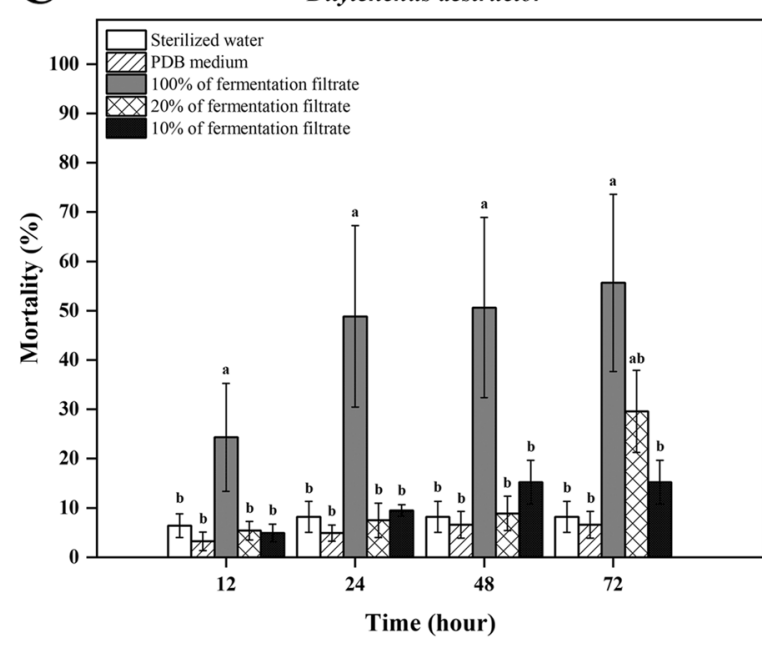

Fig. 5 In vitro nematicidal activity of the fermentation filtrate of Volutella. citrinella (GUCC2219) against three species of plant pathogenic nematodes (A. A. besseyi; B. B. xylophilus; C. D. destructor). *Note: Different letters indicate a significant difference between the different treatments within a given time point. Lowercase letters indicate significantly different means at $P<0.05$. Data represent the mean $\pm \operatorname{SE}(n=4)$

destructor was the most resistant to the fermentation broth, exhibiting a mortality rate of only $51 \%$ at $72 \mathrm{~h}$ (Fig. 5C). Collectively, the data indicate that the fermentation broth of $V$. citrinella (GUCC2219) exhibited different levels of nematicidal activity against the three different species of nematodes.

Although the nematicidal activity of the $20 \%$ preparation of the fermentation filtrate is significantly lower than that of the $100 \%$ fermentation filtrate, it still exhibited the high nematicidal activity against $A$. besseyi $(68 \%), B$. xylophilus $(48 \%)$ and $D$. destructor $(30 \%)$ at $72 \mathrm{~h}(\mathrm{P}<0.05)$. (Fig. 5A-C). A 10\% preparation of the fermentation broth also exhibited a significant level of nematicidal activity at $72 \mathrm{~h}$, relative to the controls, against B. xylophilus (33\%) and D. destructor $(15 \%)(\mathrm{P}<0.05)($ Fig. $5 \mathrm{~B}, \mathrm{C})$.

\section{Discussion}

Nematode traps are generally produced by fungi under low-nutrient or nutrient-deficient conditions but can also be induced by other agents, such as abscisic acid, amino acids, bacteria, nematodes, etc. [38]. The trap structures formed by $V$. citrinella (GUCC2219) were mainly produced under low-nutrient WA, which mainly form three ring types: small, regularly shaped; large, regularly shaped and irregularly shaped rings of various sizes. There were some differences from currently reported fungal nematode traps, such as adhesive nets, adhesive knobs, adhesive branches, and constricting rings [39]. Nematodes that are preyed upon by $V$. citronella, are entangled by the hyphae and rings. Of interest is the fact that the rings turn a golden color when the nematodes are caught. This feature has not been reported for other fungi that uses the same method of entrapment. We speculate that a chemical substance that are released when a nematode is trapped, might be responsible for the color change.

Previous studies have reported nematicidal activity of the fermentation filtrate of some fungi, such as Beauveria bassiana (Snef2621) against $A$. besseyi, exhibiting a mortality rate of $64.85 \%$ at $48 \mathrm{~h}$ [40]. In contrast, $V$. citrinella (GUCC2219) fermentation filtrates have higher nematicidal activity, and the mortality rate reached $100 \%$ at $48 \mathrm{~h}$. Wu et al. [41] reported Myrothecium verrucaria, whose fermentation filtrates exhibited a high mortality rate (96.1\%) against B. xylophilus. In our research, $V$. citrinella (GUCC2219) fermentation filtrates also had high activity 
against $B$. xylophilus, with a mortality rate of $100 \%$. The study by Zhang et al. [42] showed that Bacillus subtilis $1 \times 10^{9}$ spore/g wettable powder (WP) and Trichoderma fertilizer $\geq 2 \times 10^{8}$ spore/g dustable powder (DP) had nematicidal activity against $D$. destructor, the corrected mortality rate reached 73.45 and $44.76 \%$ at $72 \mathrm{~h}$, respectively. The activity of $V$. citrinella (GUCC2219) fermentation filtrates against $D$. destructor $(51 \%)$ was between those of these two microbial agents. The fermentation filtrate of V. citrinella (GUCC2219) had nematicidal activity against all three species of nematodes that were also evaluated, although the level of nematicidal activity differed among the three different species. Collectively, our data provide information on a new fungal strain ( $V$. citrinella) with nematicidal activity.

Compared with the previously reported commercial preparations of fungi, such as Paecilomyces lilacinus and Verticillium chlamydosporium [43], they are mainly used as endoparasitic fungi to prevent and control plant nematodes that damage plant roots, such as root knot nematodes [44], and based on In vitro studies have shown that our fungus has nematicidal activity whether it is the fungus itself or its metabolites. It has high nematicidal activity against the three nematodes that destroy the three parts of the plant. Therefore, our fungus is suitable for developing nematicides from the perspective of insecticidal ways and target nematodes. Further studies need to be conducted to the biological characteristics of the fungi and isolate its nematicidal activity substances, at the same time, determining if this is a common feature of species within the genus Volutella.

\section{Conclusions}

In the present study, we report a new nematophagous fungal strain (GUCC2219) that was isolated from cysts formed by potato cyst nematodes. The GUCC2219 strain exhibited the potential to control three species of nematodes in vitro, $A$. besseyi, B. xylophilus, and D. destructor, and the mycelia also changed from pale white to light yellow after capturing a nematode. The GUCC2219 strain was identified as $V$. citrinella based on morphological observations and a phylogenetic analysis of the DNA sequences of its ITS and LSU regions. Our finding represents a new record in China. The fungus was able to produce hyphae that formed complex ring structures capable of trapping the three different species of nematodes that were evaluated. Our results clearly demonstrated the predatory properties of the hyphal rings formed by $V$. citrinella (GUCC2219), representing a new and novel discovery. V. citrinella (GUCC2219) produced a constant number of hyphal ring structures in a low-nutrient environment and the fermentation filtrate against the three species of nematodes in a short time without being concentrated, which presumably contributed to its strong predatory activity and nematicidal properties. Our research has laid the foundation for the application of the nematophagous fungi (GUCC2219). According to the results of biological characteristics and nematicidal ways, the biological pesticides can be further developed. One is the spore suspension, and the other is nematicidal fermentation filtrate. For seed-borne diseases such as $A$. besseyi, the seeds can be soaked before sowing, or the inoculant can be sprayed on the leaves and stems of the rice; $B$. xylophilus, which are parasitic nematodes in pine trees, spores or nematicidal fermentation filtrate can be injected into the plants through a syringe; $D$. destructor, which parasitizes mainly tubers, bulbs and root crops, root irrigation can be carried out to achieve the purpose of preventing nematode diseases. Of course, these are only a bold speculation, and further research is needed to prove the applicability of this strain in the field.

\section{Methods \\ Sample collection and fungal strain isolation}

Soil samples were collected from 18 fields of potato plants growing in Weining County, Guizhou, China, that were infected by PCNs. In each field, ten plots of a $5 \times 5 \mathrm{~m}$ grid were selected surrounding infected potato plants, and in each grid, an approximate volume of $250 \mathrm{ml}$ of soil was collected from rhizosphere zone (0-20-cm depth). The individual samples of each plot were collected and mixed in a bucket to obtain a single composite sample [45]. Each composite sample was thoroughly mixed to obtain a homogenous sample. A subsample of an approximate volume of $500 \mathrm{ml}$ soil was then air-dried at $37^{\circ} \mathrm{C}$ for 2 days for PCNs cyst extraction [46-48]. Cysts were extracted from a subsample of $100 \mathrm{~g}$ of dried soil using the Baunacke method $[49,50]$, i.e., dried cysts that floated in water were decanted and collected on a $250 \mu \mathrm{m}$ sieve.

The selected cysts were surface sterilized in $0.2 \%$ $\mathrm{H}_{2} \mathrm{O}_{2}$ for 3 min following three washes with distilled water. The surface-sterilized cysts were individually placed onto $1 \%$ WA plates. Plates were incubated at room temperature and monitored regularly. Fungal mycelia growing from the cultured cysts were then recultured several times on new PDA plates. The obtained isolates were initially screened for nematode predation activity. A total of 44 isolates were screened (A. besseyi), one isolate exhibited nematode predation activity (Attached Fig. 1), which was conserved in the Culture Collection of the Department of Plant Pathology, Agriculture College, Guizhou University (GUCC) and the strain number was GUCC2219. Therefore, this fungal strain was selected for further study. 
Table 3 Primers and PCR protocols

\begin{tabular}{llll}
\hline Target DNA & Primer & Primer sequence $\mathbf{5}^{\prime} \mathbf{- \mathbf { 3 } ^ { \prime }}$ & PCR protocol \\
\hline LSU rDNA & LROR & ACCCGCTGAACTTAAGC & $95^{\circ} \mathrm{C}$ for $3 \mathrm{~min} ; 31 \mathrm{cycles}$ of $94^{\circ} \mathrm{C}$ for \\
& LR5 & TCCTGAGGGAACTTCG & $30 \mathrm{~s}, 50^{\circ} \mathrm{C}$ for $45 \mathrm{~s}$, and $72^{\circ} \mathrm{C}$ for $1 \mathrm{~min}$ \\
& & $30 \mathrm{~s} ; 72^{\circ} \mathrm{C}$ for $7 \mathrm{~min}$; and $4^{\circ} \mathrm{C}$ on hold \\
ITS rDNA & GGAAGTAAAAGTCGTAACAAGG & $95^{\circ} \mathrm{C}$ for $3 \mathrm{~min} ; 31 \mathrm{cycles}$ of $94^{\circ} \mathrm{C}$ \\
& ITS5 & for $1 \mathrm{~min}, 50^{\circ} \mathrm{C}$ for $45 \mathrm{~s}$, and $72^{\circ} \mathrm{C}$ \\
ITS4 & TCCTCCGCTTATTGATATGC 3 min; $72^{\circ} \mathrm{C}$ for $7 \mathrm{~min} ;$ and $4^{\circ} \mathrm{C}$ \\
& & on hold \\
\hline
\end{tabular}

Note: The primers were synthesized by SinGenoMax (Beijing)

\section{Collection and culturing of nematodes}

Samples of $A$. besseyi (The specimens were identified by Zaifu Yang) were collected from rice growing in Dushan County, Guizhou Province, China, and $D$. destructor was provided by the Nematode Laboratory, Fujian Agricultural and Forestry University. The nematodes were propagated on carrot callus [51]. The nematodes were removed from the carrot-callus cultures and sterilized with $0.1 \%$ streptomycin sulfate for 10 mins, washed three times with double-distilled water, and then cultured on carrot discs at $25^{\circ} \mathrm{C}$ for $30 \mathrm{~d}$.

Bursaphelenchus xylophilus was provided by the Center for Research and Development of Fine Chemicals, Guizhou University, Guiyang, China. It was cultured on PDA plates containing Botrytis cinerea [52], which was grown on PDA plates at $28^{\circ} \mathrm{C}$ for $7 \mathrm{~d}$. Nematodes were placed in the developing colony of $B$. cinerea, and the plates were incubated at $28^{\circ} \mathrm{C}$ until the $B$. cinerea colony was completely consumed. The nematodes were separated from $B$. cinerea cultured using the Baermann funnel method [50]. A nematode suspension was made at a concentration of 1000 nematodes $/ \mathrm{ml}$ for use in the predatory and nematicidal activity assays of the fungal isolates.

\section{Fermentation filtrate preparation (GUCC2219)}

For the preparation of PDB medium, $200 \mathrm{~g}$ potatoes were added to $1 \mathrm{~L}$ of distilled water and boiled for 30 mins. The mixture was then filtered through double gauze, and $20 \mathrm{~g}$ dextrose was added to the filtrate. Subsequently, $100 \mathrm{ml}$ aliquots of the prepared PDB medium were placed into $250 \mathrm{ml}$ conical flasks and sterilized in an autoclave at $121^{\circ} \mathrm{C}$ for $30 \mathrm{~min}$. A single pure culture of the GUCC2219 isolate was cut into small pieces approximately $5 \mathrm{~mm}$ in diameter using a sterilized cutting blade. Five pieces were added into to $100 \mathrm{ml}$ of sterilized PDB medium, which was then placed on a rotary shaker at $28^{\circ} \mathrm{C}$ set at $200 \mathrm{rpm}$ for 7 days. Afterwards. the medium was filtered and stored at $4{ }^{\circ} \mathrm{C}$.

\section{Morphological observations (GUCC2219)}

The GUCC2219 isolate was inoculated on two types of different media, PDA and CMA, and cultured at $25^{\circ} \mathrm{C}$ for $15 \mathrm{~d}$. Photographs of the colonies, mycelia, and mycelial structures were taken using a stereomicroscope (Keyence VHX-7000 digital microscope). Sections of the fungal colonies were made with the assistance of a stereomicroscope (Leica S9i) and mounted in water. Photomicrographs of conidiophores and conidia were taken using a compound light microscope (Zeiss Scope 5) equipped with an AxioCam 208 color camera.

\section{DNA extraction, PCR, and sequencing (GUCC2219)}

The GUCC2219 fungal isolate was grown on PDA at $25^{\circ} \mathrm{C}$ for $15 \mathrm{~d}$. The resulting mycelia were then scraped off the surface of the plate with a sterile scalpel. Total genomic fungal DNA was extracted using a BIOMIGA Fungus Genomic DNA Extraction Kit (GD2416, BIOMIGA, San Diego, California, USA) following the manufacturer's protocol. ITS and LSU were PCR-amplified using the primer pair ITS5/ITS4 [53] and LR0R/LR5 [54] (Table 3), respectively. PCRs were conducted in a $25 \mu \mathrm{l}$ reaction mixture containing $10 \mu \mathrm{l} 2 \times$ Bench Top Taq Master Mix

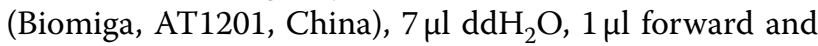
reverse primers $(10 \mu \mathrm{M} / \mu \mathrm{l})$, and $1 \mu \mathrm{l}$ DNA template. PCR products were commercially sequenced by using the same PCR primers used in the amplification reactions by SinoGenoMax (Beijing).

\section{Phylogenetic analysis (GUCC2219)}

Sequences of each gene generated from forward and reverse primers were assembled with BioEdit v.7.2.5 [55], and consensus sequences were then combined with related sequences downloaded from National Center for Biotechnology Information (NCBI) (Table 4). Each gene dataset was aligned separately using Mafft v7.187 [56] and manually aligned where necessary. A phylogenetic tree was constructed based on the ITS and LSU sequences as a concatenated dataset using the maximum likelihood (ML) method at the CIPRES web portal [57]. ML was performed using "RAxML-HPC BlackBox" tool [58]. Trees were sampled every 100 generations, 
Table 4 GenBank accession numbers of strains used in the phylogenetic analysis

\begin{tabular}{llll}
\hline Species & Strain no. & \multicolumn{2}{l}{ GenBank no. } \\
\cline { 3 - 4 } & & ITS & LSU \\
\hline Volutella ciliata & CBS 483.61 & KM231770 & KM231635 \\
V. ciliata & KNU-516 & KM267564 & - \\
V. citrinella & DAOM:226720 & HQ897821 & HQ843771 \\
V. delonicis & MFLU 19-1384 & NR_171101 & NG_073864 \\
V.lini & CABI:IMI92688 & JQ647452 & - \\
V.lini & CABI:IMI224502 & JQ693169 & - \\
V. ramkumarii & CABI IMI136704 & JQ647453 & - \\
V. thailandensis & MFLUCC 16-0366 & MH388368 & MH376742 \\
Calostilbe striispora & CBS 133491 & KM231789 & KM231653
\end{tabular}

Note:"-" represent the GenBank number doesn't exist

and runs were stopped automatically when the average standard deviation of split frequencies fell below 0.01. A $50 \%$ majority rule consensus tree was summarized after discarding the first $25 \%$ samples. The resulting tree was visualized in FigTree v1.4.3 [59] and by Adobe Illustrator CC 2019.

\section{In vitro predatory activity of the fungal isolates against nematodes}

In the preliminary screening, a $5 \mathrm{~mm}$-diameter disc of mycelium was taken from the margin of the fungal isolates, transferred to the center of a Petri dish containing $1 \% \mathrm{WA}$, and then incubated in the dark at $25^{\circ} \mathrm{C}$ for 2 weeks. After the incubation period, Petri dishes were inoculated with a $1 \mathrm{ml}$ nematode suspension containing 1000 nematodes. The nematode suspension was divided into 4-5 drops and spread uniformly inside the periphery of the fungal colonies. Plates without fungi served as controls. The morphology and the average size of the hyphal rings were observed and recorded. Four replicates of each isolate were utilized. The number of nematodes captured in the hyphal rings was counted using a stereomicroscope (Leica S9i, Germany). Microscopic images were captured with a compound light microscope (Zeiss Scope 5) equipped with an AxioCam 208 color camera.

\section{Nematicidal activity of the fungal fermentation filtrate (GUCC2219)}

A $100 \mu \mathrm{l}$ suspension of nematodes containing approximately 100 nematodes was placed into wells of a 96-well culture plate containing different concentrations (100, 20, $10 \%)$ of the fermentation broth. Control wells contained distilled water. The plate was incubated at $28^{\circ} \mathrm{C}$ for $72 \mathrm{~h}$. Nematodes were microscopically monitored after 12 , 24,48 , and $72 \mathrm{~h}$. At each timepoint, the nematodes were washed and transferred into distilled water to observe their motility as an indication of nematicidal activity. Nematodes were considered dead when they remained immotile upon probing with a fine hair needle, and percentage mortality was calculated. Four replicates were analyzed for each concentration and for the control.

\section{Data analysis}

The data were subjected to two-way analysis of variance (ANOVA), with concentration and posttreatment time (exposure period) serving as the main treatment effects and concentration $x$ time as the interaction. Significant differences between means were determined at $P<0.05$ using Duncan's multiple range. All statistical analyses were conducted in MS Excel and SPSS statistics (version 19.0) software. Figures were generated using Origin 2018.

\begin{abstract}
Abbreviations
PPNs: Plant parasitic nematodes; PCNs: Potato cyst nematodes; ITS: Internal transcribed spacer; LSU: Large subunit; PCRs: polymerase chain reactions; BLAST: Basic Local Alignment Search tool; PDA: Potato dextrose agar; CMA: Cornmeal agar; WA: Water agar; PDB: Potato dextrose broth; WP: Wettable powder; DP: Dustable powder; NCBI: National Center for Biotechnology Information; ANOVA: Analysis of variance.
\end{abstract}

\section{Supplementary Information}

The online version contains supplementary material available at https://doi. org/10.1186/s12866-021-02385-x.

Additional file 1: Schedule 1. Some genera or species distributed by nematophagous fungi.

\section{Acknowledgments}

We thank Prof. Michael Wisniewski (Virginia Polytechnic Institute and State University, Blacksburg, VA, USA) for his critical reading of the manuscript.

\section{Authors' contributions}

$Z Y$ and $Y W$ designed and supervised the study and reviewed the manuscript for intellectual content. XZ (Xinyue Zhang) conducted the laboratory and data analysis and drafted the manuscript. $\mathrm{HZ}, \mathrm{SW}, \mathrm{QB}$ participated in the laboratory analysis. YW, XX, XZ (Xiangyu Zeng), CL, ZJ, XG and ZL reviewed the manuscript for intellectual content. All authors read and approved the final version of the manuscript.

\section{Funding}

This study was funded by the Science and Technology Project of Guizhou Tobacco Company (NO. 201618), Science and Technology Project of Bijie Branch of Guizhou Tobacco Company (NO. 201652050024142), Guizhou Province Plant Pathology Science and Technology Innovation Talent Team (NO. 20205001), and Guizhou University Talent Introduction Research Project (NO. 2009003).

\section{Availability of data and materials}

The datasets used and/or analyzed during the current study are available from the corresponding author on reasonable request. 


\section{Declarations}

Ethics approval and consent to participate

Not applicable.

\section{Consent for publication}

Not applicable.

\section{Competing interests}

The authors declare that they have no competing interests.

\section{Author details}

${ }^{1}$ Department of Plant Pathology, College of Agriculture, Guizhou University, Guiyang, Guizhou, China. ${ }^{2}$ Guizhou Station of Plant Protection and Quarantine, Guiyang, Guizhou, China. ${ }^{3}$ Center for Research and Development of Fine Chemicals, Guizhou University, Guiyang, Guizhou, China.

\section{Received: 4 August 2021 Accepted: 8 November 2021}

Published online: 22 November 2021

\section{References}

1. Decraemer W, Hunt DJ. Structure and classification. In: Perry RN, Moens M, editors. Plant Nematology. CABl; 2006. p. 3-32. https://doi.org/10. 1079/9781845930561.0003.

2. Ali MA, Abbas A, Azeem F, Javed N, Bohlmann H. Plant-nematode interactions: from genomics to metabolomics. Int J Agric Biol. 2015;17(6):107182. https://doi.org/10.17957/IJAB/15.0037.

3. Webster JM. The host-parasite relationships of plant-parasitic nematodes. Adv Parasitol. 1969;7:1-40. https://doi.org/10.1016/S0065-308X(08) 60433-9.

4. Williamson VM, Gleason CA. Plant-nematode interactions. Curr Opin Plant Biol. 2003;6(4):327-33. https://doi.org/10.1016/\$1369-5266(03)00059-1.

5. Curtis RHC. Plant parasitic nematode proteins and the host parasite interaction. Brief Funct Genomics. 2007;6(1):50-8. https://doi.org/10.1093/ BFGP/ELM006.

6. Nicol JM, Turner SJ, Coyne DL, den Nijs L, Hockland S, Maafi ZT. Current nematode threats to world agriculture. In: Jones J, Gheysen G, Fenoll C, editors. Genomics and molecular genetics of plant-nematode interactions. Springer: Dordrecht; 2011. p. 21-34. https://doi.org/10.1007/ 978-94-007-0434-3.

7. Shukla N, Kaur P, Kumar A. Molecular aspects of plant-nematode interactions. Ind J Plant Physiol. 2016;21(4):477-88. https://doi.org/10.1007/ s40502-016-0263-y.

8. Abdel-Baset SH, Dawabah AAM. Phytonematodes associating wheat in north eastern Egypt and pathogenicity of Heterodera avenae on certain cereal cultivars. Int J Phytopathol. 2020;9(3):165-72. https://doi.org/10. 33687/phytopath.009.03.3434

9. Xu X, Qing X, Xie JL, Yang F, Peng YL, Ji HL. Population structure and species delimitation of rice white tip nematode, Aphelenchoides besseyi (Nematoda: Aphelenchoididae), in China. Plant Pathol. 2020;69(1):159-67. https://doi.org/10.1111/ppa.13113.

10. Kumar KK, Dara SK. Fungal and bacterial endophytes as microbial control agents for plant-parasitic nematodes. Int J Environ Res Public Health. 2021;18(8):4269. https://doi.org/10.3390/ijerph18084269.

11. Kanzaki N, Giblin-Davis RM, Scheffrahn $\mathrm{RH}$, Taki H, Esquivel A, Davies KA, et al. Reverse taxonomy for elucidating diversity of insect-associated nematodes: a case study with termites. PLoS One. 2012;7(8):e43865. https://doi.org/10.1371/journal.pone.0043865

12. Bridge J, Plowright RA, Peng D. Nematode parasites of rice. In: Luc M Sikora RA, Bridge J, editors. Plant parasitic nematodes (PPNs) in subtropical and tropical agriculture: CABl; 2005. p. 87-130. https://doi.org/10. 1079/9780851997278.0087

13. Jones JT, Haegeman A, Danchin EGJ, Gaur HS, Helder J, Jones MGK, et al. Top 10 plant-parasitic nematodes in molecular plant pathology. Mol Plant Pathol. 2013;14(9):946-61. https://doi.org/10.1111/mpp.12057.

14. Filipiak A, Malewski T, Matczyńska E, Tomalak M. Molecular variation among virulent and avirulent strains of the quarantine nematode
Bursaphelenchus xylophilus. Mol Gen Genomics. 2021;296(2):259-69. https://doi.org/10.1007/s00438-020-01739-w.

15. Evans HF, McNamara GD, Braasch H, Chadouef J, Magnusson C. Pest risk analysis (PRA) for the territories of the European Union (as PRA area) on Bursaphelenchus xylophilus and its vectors in the genus Monochamus. OEPP/EPPO. 1996;26:199-249. https://doi.org/10.1111/j.1365-2338. 1996.tb00594.x.

16. Togashi K, Shigesada N. Spread of the pinewood nematode vectored by the Japanese pine sawyer: modeling and analytical approaches. Popul Ecol. 2006;48(4):271-83. https://doi.org/10.1007/ s10144-006-0011-7.

17. Shinya R, Morisaka H, Kikuchi T, Takeuchi Y, Ueda M, Futai K. Secretome analysis of the pine wood nematode Bursaphelenchus xylophilus reveals the tangled roots of parasitism and its potential for molecular mimicry. PLoS One. 2013;8(6):e67377. https://doi.org/10.1371/journal.pone. 0067377.

18. Carnegie AJ, Venn T, Lawson S, Nagel M, Wardlaw T, Cameron N, et al. An analysis of pest risk and potential economic impact of pine wilt disease to Pinus plantations in Australia. Austral For. 2018;81:1-13. https:// doi.org/10.1080/00049158.2018.1440467.

19. Lee JP, Sekhon SS, Kim JH, Kim SC, Cho BK, Ahn JY, et al. The pine wood nematode Bursaphelenchus xylophilus and molecular diagnostic methods. Mol Cell Toxicol. 2020;17:1-13. https://doi.org/10.1007/ s13273-020-00110-9.

20. Jin H, Cui HY, Yang XY, Xu LH, Li XD, Liu RT, et al. Nematicidal activity against Aphelenchoides besseyi and Ditylenchus destructor of three biflavonoids, isolated from roots of Stellera chamaejasme. J Asia Pac Entomol. 2018;21(4):1473-8. https://doi.org/10.1016/j.aspen.2018.11. 013.

21. Huang WK, Peng DL, Zhang DS, Jiang HY, Ding Z, Peng H, et al. Assessment of genetic variability in population of Ditylenchus destructor (Thorne1945) (Tylenchida: Anguinidae) from China. Russ J Nematol. 2010;18(1):19-30.

22. Fan WJ, Wei ZR, Zhang M, Ma PY, Liu GL, Zheng JL, et al. Resistance to Ditylenchus destructor infection in sweet potato by the expression of small interfering RNAs targeting unc-15, a movement-related gene. Phytopathology. 2015;105(11):1458-65. https://doi.org/10.1094/ PHYTO-04-15-0087-R

23. Yang LL, Huang Y, Liu J, Ma L, Mo MH, Li WJ, et al. Lysinibacillus mangiferahumi sp. nov., a new bacterium producing nematicidal volatiles. Antonie Van Leeuwenhoek. 2012;102:53-9. https://doi.org/10.1007/ s10482-012-9712-4

24. Glare T, Caradus J, Gelernter W, Jackson T, Keyhani N, KÖhl J, et al. Have biopesticides come of age? Trends Biotechnol. 2012;30(5):250-8. https:// doi.org/10.1016/j.tibtech.2012.01.003.

25. Zhang Y, Li GH, Zhang KQ. A review on the research of nematophagous fungal species. Mycosystema. 2011;30(6):836-45. https://doi.org/10. 13346/j.mycosystema.2011.06.003.

26. Jiang $X Z$, Xiang MC, Liu XZ. Nematode-trapping fungi. Microbiol Spectr. 2017;5(1):1-12. https://doi.org/10.1128/microbiolspec FUNK-0022-2016.

27. Zhou CN, Wu SH, Shao QH, Cao L, Wang L. A brief talk on the research Progress of biological control of plant parasitic nematodes. China Plant Protections. 2004;24(8):30-3. https://doi.org/10.3969/j.issn.1672-6820. 2004.08.004

28. Hastuti LDS, Yurnaliza Y, Tarigan WE, Hartanto A, Pahlevi S. Isolation of Nematophagous Fungi from Lau Kawar Lake, North Sumatra. Indonesia Journal of Physics: Conf Ser. 1819;2021(1):012065. https://doi.org/10. 1088/1742-6596/1819/1/012065.

29. Ocampo-Gutiérrez AY, Hernández-Velázquez VM, Aguilar-Marcelino L, Cardoso-Taketa A, Zamilpa A, López-Arellano ME, et al. Morphological and molecular characterization, predatory behaviour and effect of organic extracts of four nematophagous fungi from Mexico. Fungal Ecol. 2021;49:101004. https://doi.org/10.1016/j.funeco.2020.101004.

30. Gräfenhan T, Schroers HJ, Nirenberg HI, Seifert KA. An overview of the taxonomy, phylogeny, and typification of nectriaceous fungi in Cosmospora, Acremonium, fusarium, Stilbella, and Volutella. Stud Mycol. 2011;68:79113. https://doi.org/10.3114/sim.2011.68.04.

31. Babu AG, Kim SW, Yadav DR, Adhikari M, Kim C, Lee HB, et al. A new record of Volutella ciliata isolated from crop field soil in Korea. Mycobiology. 2015;43(1):71-4. https://doi.org/10.5941/MYCO.2015.43.1.71 
32. Seifert KA. A monograph of Stilbella and allied hyphomycetes. Stud Mycol. 1985;27:1-235. https://doi.org/10.2307/3807446.

33. Hansel CM, Zeiner CA, Santelli CM, Webb SM. Mn (II) oxidation by an ascomycete fungus is linked to superoxide production during asexual reproduction. Proc Natl Acad Sci U S A. 2012;109(31):12621-5. https://doi. org/10.1073/pnas.1203885109.

34. Osono T, Takeda H. Microfungi associated with Abies needles and Betula leaf litter in a subalpine coniferous forest. Can Journal Microbiol. 2007;53:1-7. https://doi.org/10.1139/W06-092.

35. Šafránková I. Volutella leaf blight and stem canker on Japanese pachysandra in the Czech Republic. Plant Prot Sci. 2007;43(1):10-2. https://doi.org/ 10.17221/2350-PPS.

36. Shi F, Hsiang T. Pseudonectria buxi causing leaf and stem blight on Buxus in Canada. Eur J Plant Pathol. 2014;138:763-73. https://doi.org/10.1007/ s10658-013-0348-7.

37. Rezakhani F, Khodaparast SA, Masigol H, Roja-Jimenez K, Grossart HP, Bakhshi M. A preliminary report of aquatic hyphomycetes isolated from Anzali lagoon (Gilan province, north of Iran). Rostaniha. 2019;20(2):12343. https://doi.org/10.22092/BOTANY.2019.126701.1161.

38. Su H, Zhao Y, Zhou J, Feng H, Jiang D, Zhang KQ, et al. Trapping devices of nematode-trapping fungi: formation, evolution, and genomic perspectives. Biol Rev. 2017;92(1):357-68. https://doi.org/10.1111/brv.12233.

39. Ahren $D$, Tunlid A. Evolution of parasitism in nematode-trapping fungi. J Nematol. 2003;35(2):194-7. https://doi.org/10.1034/j.1600-0684.2003. 00020.x.

40. Zhao D, Liu B, Wang Y, Zhu X, Duan Y, Chen L. Screening for nematicidal activities of Beauveria bassiana and associated fungus using culture filtrate. Afr J Microbiol Res. 2013;7(11):974-8.

41. Wu HY, Zhang LY, Zhou XB. Effects of Myrothecium verrucaria ZW-2 fermentation filtrates on various plant-parasitic nematodes. J Plant Dis Prot. 2020;127:545-52. https://doi.org/10.1007/s41348-020-00336-8.

42. Zhang N, Wang D, Zhao YA, Qiu TY, Fu YC, Meng HW, et al. Indoor contract activities of several chemicals and microbial agents against Ditylenchus destructor. Plant Prot. 2021;47(2):276-83. https://doi.org/10.16688/j.zwbh. 2020091.

43. Liu XY, Min Y, Rao B, Chen W, Zhou RH, Wang KM. Research advances on the nematodes. Chinese J Biol Control. 2021;37(03):592-7. https://doi. org/10.16409/j.cnki.2095-039x.2021.01.004.

44. Simon LS, Pandey A. Antagonistic efficacy of Paecilomyces lilacinus and Verticillium chlamydosporium against Meloidogyne incognita infecting okra. Indian J Nematol. 2010;40(1):113.

45. Southey JF. Methods for detection of potato cyst nematodes. OEPP/EPPO. 1974;4(4):463-73. https://doi.org/10.1111/j.1365-2338.1974.tb02394.x.

46. Been $\mathrm{TH}$, Schomaker $\mathrm{CH}$. Development and evaluation of sampling methods for fields with infestation foci of potato cyst nematodes (Globodera rostochiensis and G. pallida). Phytopathology. 2000;90(6):647-56. https://doi.org/10.1094/PHYTO.2000.90.6.647.
47. Reid A, Pickup J. Molecular characterization of a morphologically unusual potato cyst nematode*. OEPP/EPPO. 2005;35(1):69-72. https://doi.org/10. 1111/j.1365-2338.2005.00810.x.

48. Nurjanah TYA, Indarti S, Hartono S. Identification, distribution and genetic diversity of the golden potato cyst nematode (Globodera rostochiensis) in Java Indonesia. AIP Conf Proc. 2016;1755:130006. https://doi.org/10. 1063/1.4958550.

49. Baunacke W. Investigations on biology and control of beet nematodes, Heterodera schachtii Schmidt. Arbeiten aus der Biologischen Reichsanstalt. 1922;11:185-288.

50. Hallman J, Viaene N. PM 7/119 (1) nematode extraction. OEPP/EPPO. 2013;43(3):471-95. https://doi.org/10.1111/epp.12077.

51. Tulek A, Kepenekci I, Cobanoglu S, Hekimhan H, Devran Z, Melik B, et al. A new culturing method for the rice white tip nematode, Aphelenchoides besseyi Christie, 1942, on carrot discs. Russ J Nematol. 2009;17(2):135-6.

52. Shi J, Chen F, Luo YQ, Wang Z, Xie BY. First isolation of pine wood nematode from pinus tabuliformis forests in China. Forest Pathol. 2012;43(1):59-66. https://doi.org/10.1111/j.1439-0329.2012.00793.x.

53. White TJ, Bruns T, Lee S, Taylor J. Amplification and direct sequencing of fungal ribosomal RNA genes for phylogenetics. PCR protocols: a guide to methods and applications. 1990;18(1):315-22. https://doi.org/10.1016/ B978-0-12-372180-8.50042-1.

54. Perera RH, Hyde KD, Maharachchikumbura SSN, Jones EBG, McKenzie EHC, Stadler M, et al. Fungi on wild seeds and fruits. Mycosphere. 2020;11(1):2108-480. https://doi.org/10.5943/mycosphere/11/1/14

55. Hall T. BioEdit: a user-friendly biological sequence alignment editor and analysis program for windows 95/98/NT. Nucleic Acids Symp Ser. 1999;41:95-8. https://doi.org/10.1021/bk-1999-0734.ch008.

56. Katoh K, Standley DM. MAFFT multiple sequence alignment software version 7: improvements in performance and usability. Mol Biol Evol. 2013;30(4):772-80. https://doi.org/10.1093/molbev/mst010.

57. Miller MA, Pfeiffer W, Schwartz T. Creating the CIPRES Science Gateway for Inference of Large Phylogenetic Trees. Gateway Computing Environments Workshop (GCE); 2010. p. 1-8. https://doi.org/10.1109/GCE.2010. 5676129.

58. Stamatakis A. RAxML-VI-HPC: maximum likelihood-based phylogenetic analyses with thousands of taxa and mixed models. Bioinformatics. 2006;22:2688-90. https://doi.org/10.1093/bioinformatics/btl446 Source: PubMed.

59. Rambaut A. Figtree version 1.4.0. 2012. Distributed by the author via: http://tree.bio.ed.ac.uk/software/figtree.

\section{Publisher's Note}

Springer Nature remains neutral with regard to jurisdictional claims in published maps and institutional affiliations.
Ready to submit your research? Choose BMC and benefit from:

- fast, convenient online submission

- thorough peer review by experienced researchers in your field

- rapid publication on acceptance

- support for research data, including large and complex data types

- gold Open Access which fosters wider collaboration and increased citations

- maximum visibility for your research: over $100 \mathrm{M}$ website views per year

At BMC, research is always in progress.

Learn more biomedcentral.com/submissions 